\title{
Influence of order-disorder transitions on oxygen permeability through selected nonstoichiometric perovskite-type oxides
}

\author{
H. Kruidhof, H.J.M. Bouwmeester ${ }^{1}$, R.H.E. v. Doorn and A.J. Burggraaf \\ Laboratory for Inorganic Chemistry, Materials Science and Catalysis, Department of Chemical Technology, University of Twente, \\ PO Box 217, 7500 AE Enschede, The Netherlands
}

\begin{abstract}
New results on the oxygen permeability of perovskite-type oxides $\mathrm{SrCo}_{0.8} \mathrm{~B}_{0.2}^{\prime} \mathrm{O}_{3-\delta}$ (with $\mathrm{B}^{\prime}=\mathrm{Cr}, \mathrm{Fe}, \mathrm{Co}$ and $\mathrm{Cu}$ ) and $\mathrm{La}_{0.6} \mathrm{Sr}_{0.4} \mathrm{CoO}_{3-\delta}$ are presented. The occurrence of order-disorder transitions at elevated temperatures $\left(790-940^{\circ} \mathrm{C}\right)$ in these phases has been confirmed by DSC measurements and, in some cases, by X-ray powder diffraction of samples either slowly cooled or quenched from high temperature after annealing in different atmospheres. The oxygen permeability found upon exposing opposite sides of sealed disc specimens to a stream of air and of helium, respectively, increases sharply (between 5-6 orders of magnitude up to $0.3-3 \times 10^{-7} \mathrm{~mol} \mathrm{~cm}^{-2} \mathrm{~s}^{-1}$ ) at the onset of the transition from a low-temperature vacancy-ordered state to defect perovskite, except for $\mathrm{SrCo}_{0.8} \mathrm{Fe}_{0.2} \mathrm{O}_{3-\delta}$. In the latter case only a slight anomaly is found in the Arrhenius plot of the oxygen permeability at $\sim 790^{\circ} \mathrm{C}$. The comparatively high oxygen flux through $\mathrm{SrCo}_{0.8} \mathrm{Fe}_{0.2} \mathrm{O}_{3-\delta}$ observed at intermediate temperatures is interpreted in terms of a two-phase mixture of a vacancy-ordered state and disordered perovskite, while above $\sim 790^{\circ} \mathrm{C}$ the sample is single-phase of defect perovskite structure.
\end{abstract}

\section{Introduction}

Perovskite oxides are characterized by a large ability to tolerate departures from ideal stoichiometry $\mathrm{ABO}_{3}[1]$. The latter results either from the substitution with aliovalent cations or from redox processes associated with the presence of transition metal atoms which can adopt different formal oxidation states. Anion deficient nonstoichiometry has often been reported and extensive studies using X-ray diffraction, electron diffraction and HREM have shown that, particularly at low temperature, many different vacancy-ordered structures can occur to accommodate the large compositional variations $[2,3]$. The proposed structural frameworks can often be derived from the ideal perovskite lattice by loss of oxygen. The oxygen vacancies tend to disorder at elevated temperatures, maximizing their configurational entropy, and may then become highly mobile [4].

Teraoka et al. [5-7] were the first to measure very high permeability fluxes through defect perovskite-

1 To whom correspondence should be addressed. type $\mathrm{LnCoO}_{3}$-based compositions with appreciable acceptor doping on either A or B sites necessary to produce the highly mobile oxygen vacancies. The oxygen fluxes measured through the oxides exhibiting high electronic conductivity were found to be related to the extent of oxygen ion conductivity which can become greater by a factor of 10-100 than that of the stabilized zirconias $[7,8]$. The perovskite compositions are therefore targeted in basic SOFC materials research aiming to develop ceramic electrodes with improved mixed ionic-electronic conductivity to reduce polarization losses at the electrode/electrolyte interface and have been claimed for potential use as oxygen separation membranes at elevated temperatures $[4,9,10]$.

The aim of our ongoing research is the screening of mixed ionic-electronic conducting oxides for utilization as ceramic membranes designed for selective feeding of oxygen in chemical reactors aiming to improve the selectivity and yield for various oxidation reactions. Apart from easy decomposition of the cobaltites at low oxygen pressure [11,12], ample evidence has been provided that vacancy-ordered 
structures can occur in these nonstoichiometric solids to a degree which depends both upon the thermal history and upon the oxygen content [1-3]. In preliminary investigations on perovskite-type oxides $\mathrm{SrCo}_{0.8} \mathrm{Fe}_{0.2} \mathrm{O}_{3-\delta}$ and $\mathrm{La}_{0.6} \mathrm{Sr}_{0.4} \mathrm{CoO}_{3-\delta}$ we found that the oxygen permeability at intermediate temperatures $\left(650-750^{\circ} \mathrm{C}\right)$ decreased asymptotically with time which we attributed to processes associated with the ordering of oxygen vacancies in these phases. The end values of the permeability in both cases were found to be significantly lower than reported by Teraoka et al. [5]. This paper reports first results using combined oxygen permeability measurements, X-ray powder diffraction and thermal analysis in an attempt to throw further light on these observations. A detailed presentation of results obtained from this study will be presented elsewhere [13].

\section{Experimental}

Perovskite oxide powders were prepared by the liquid citrate method using high purity raw materials. A detailed description of the synthesis route has been given earlier [14].

Stoichiometric amounts of the appropriate metal nitrates were dissolved in diluted nitric acid. Citric acid was added to the solution (acid/metal mole ratio 2:1), the $\mathrm{pH}$ being adjusted with $\mathrm{NH}_{4} \mathrm{OH}$ to between 3-3.5. An aliquot of this solution was then evaporated on a hot plate until pyrolysis took place. The calcination of the powders was carried out in a platinum-lined alumina boat in air at $1000-1100^{\circ} \mathrm{C}$ for five hours. After grinding in a ball mill using acetone, the powders thus obtained were isostatically pressed (200 MPa) into rods which were sintered in air at $1160^{\circ} \mathrm{C}$ for five hours with heating and cooling rates of $2^{\circ} \mathrm{C} \mathrm{min}^{-1}$. These rods showed densities between $93-99 \%$ of their theoretical value.

Initial characterization in each case was by $\mathrm{X}$-ray powder diffraction (XRD) recorded with a Philips diffractometer using nickel-filtered $\mathrm{Cu} \mathrm{K} \alpha$ radiation and combined thermogravimetric measurements and differential scanning calorimetry (TG-DSC) using a Stanton Redcroft model STA 625 thermal analyzer.

For oxygen permeability measurements, the sintered rods were sliced into discs of $12 \mathrm{~mm}$ diameter. Both sides of the discs were ground and polished with
SiC paste ( 1000 mesh) to give a final thickness of either 1 or $2 \mathrm{~mm}$. The discs were then mounted to the end of a quartz tube using a pyrex glass seal (trade name Duran, Schott Nederland B.V.). During the measurements, one side of the disc was exposed to either air or an oxygen/nitrogen mixture, while the other was exposed to a flow of helium with flow rates on both sides between $1-50 \mathrm{~cm}^{3} \mathrm{~min}^{-1}$. The experimental apparatus has been described in detail elsewhere [15].

The amount of oxygen which permeated through the specimen was determined both by on-line gaschromatography (Varian model 3400 ) and by a zirconia sensor at the gas outlet. Good agreement was noted between the data from both measurements. Gas leakage through cracks or pores, if present, could be detected gas-chromatographically by the presence of nitrogen in the helium stream, using a molecular sieve column (80-100 mesh, $6 \mathrm{ft}$. s.s.) to separate oxygen and nitrogen.

Permeability data were collected at temperatures $600-1050^{\circ} \mathrm{C}$ with oxygen partial pressures maintained at the high pressure side varying between $1-$ $100 \mathrm{kPa}$. Measured oxygen fluxes, $j_{\mathrm{O}_{2}}\left(\mathrm{~mol} \mathrm{~cm}^{-2}\right.$ $\mathrm{s}^{-1}$ ), were normalized to the permeating surface at that side, disregarding edge effects associated with the sealing procedure. Different helium gas flow rates were used to see whether the permeability was controlled by the oxygen pressure exposed to the low pressure side. Oxygen desorption measurements (or adsorption in the reversed experiment) were started to study the (re)equilibration kinetics towards steady-state oxygen permeation. The amount of oxygen in the carrier gas (helium) released by a disc specimen was measured as a function of time either after switching from air to helium gas or after a stepwise change in the temperature, using techniques as described above.

\section{Results and discussion}

In this work we mainly concentrated on obtaining oxygen permeability data for perovskite compositions $\mathrm{SrCo}_{0.8} \mathrm{~B}_{0.2}^{\prime} \mathrm{O}_{3-\delta}$ (with $\mathrm{B}^{\prime}=\mathrm{Cr}, \mathrm{Fe}, \mathrm{Co}$ and $\mathrm{Cu}$ ), of which the parent structure, $\mathrm{SrCoO}_{3-\delta}$, is known to transform reversibly from a low-temperature vacancy ordered state to defect perovskite at about 
$900^{\circ} \mathrm{C}$. Preliminary data are presented for $\mathrm{La}_{0.6} \mathrm{Sr}_{0.4} \mathrm{CoO}_{3-\delta}$. Results from detailed investigations of the oxygen permeability as a function of the oxygen pressure gradient imposed across the disc specimens will be the subject of a forthcoming paper [13].

\section{1. $\mathrm{SrCoO}_{3-\delta}$}

Oxygen-deficient $\mathrm{SrCoO}_{3-\delta}$ can adopt a number of structures, e.g. cubic, orthorhombic, tetragonal, depending on annealing temperature and the oxygen partial pressure maintained during the synthesis. The preparation under the conditions mentioned in the experimental section led to a, poorly defined, "hexagonal" structure which is known to be the low-temperature phase of $\mathrm{SrCoO}_{3-\delta}$. X-ray analysis revealed a powder pattern in good agreement with those published previously [16-18].

Difficulties have been reported to obtain a precise structure determination of the "hexagonal" phase whose structure has been described as being of the $2 \mathrm{H}-\mathrm{BaNiO}_{3}$ type with some vacancy ordering [16,17]. Rodriguez and González-Calbet [18] have claimed, on the basis of data from electron-diffraction and X-ray powder diffraction, a rhombohedral structure (6R) with cell parameters $a=9.426(3)$ and $c=12.495$ (4) $\AA$ (hexagonal setting). The proposed structural model can be derived from cubic perovskite (with ideal stoichiometry $\mathrm{SrCoO}_{3}$ ), by a six $\mathrm{SrO}_{3-\delta}$ layer stacking sequence along the cubic [111] direction leaving Co ions in oxygen octahedra. More recently, it has been suggested from data of Mössbauer spectroscopy on ${ }^{57} \mathrm{Fe}$ doped $\mathrm{SrCoO}_{3-\delta}$ that the "hexagonal" phase is closely related to the brownmillerite lattice (with ideal stoichiometry $\mathrm{SrCoO}_{2.5}$ ) which contains alternate layers of high spin $\mathrm{Co}^{3+}$ on tetrahedral $(\mathrm{T})$ and octahedral $(\mathrm{O})$ sites [19-21]. The occurrence of low spin $\mathrm{Co}^{3+}$ on the presumed tetrahedral sites in the "hexagonal" phase would explain the about $11 \%$ smaller volume relative to the brownmillerite lattice [16,22].

The "hexagonal" phase transforms reversibly to defect perovskite at about $900^{\circ} \mathrm{C}[17,22]$. Our results from TG-DSC measurements are in reasonable agreement with those given by Takeda et al. [17]. Fig. 1 shows that the permeability in the apparently ordered material is extremely low (with values as low

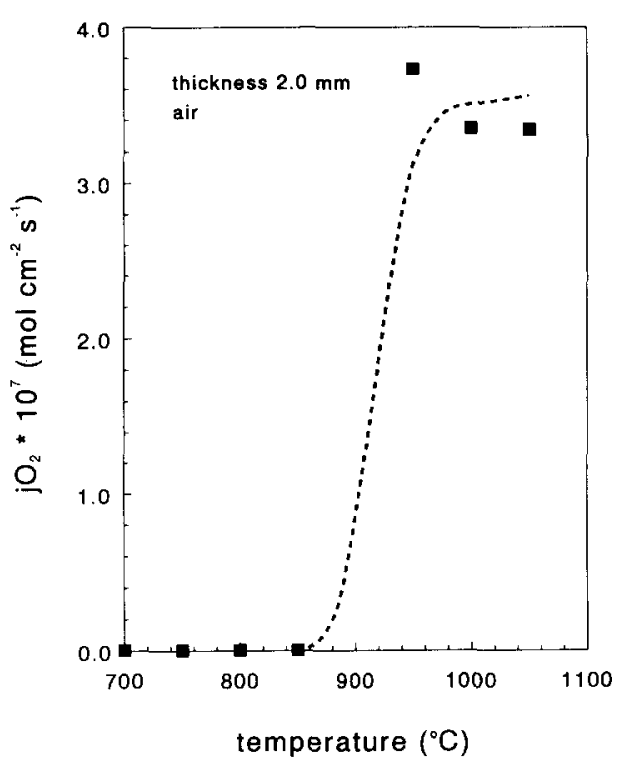

Fig. 1. Oxygen permeability data for $\mathrm{SrCoO}_{3-\delta}$. The dashed line is a guide to the eye.

as $10^{-12}-10^{-11} \mathrm{~mol} \mathrm{~cm}^{-2} \mathrm{~s}^{-1}$, which are close to the detection limit of our apparatus), while increasing sharply over more than five orders of magnitude at the onset of the order-disorder transition.

\section{2. $\mathrm{SrCo}_{0.8} \mathrm{Fe}_{0.2} \mathrm{O}_{3-\delta}$}

The X-ray powder pattern of phase $\mathrm{SrCo}_{0.8} \mathrm{Fe}_{0.2} \mathrm{O}_{3-\delta}$ could be indexed on the basis of a cubic perovskite with $a=3.8719(5) \AA$. Some additional diffraction lines with very small relative intensities were present which might indicate ordering on a $2 a \times 2 a$ superlattice. A sample slowly cooled from $700^{\circ} \mathrm{C}$ after annealing in a helium gas stream for $48 \mathrm{~h}$ gave a completely different pattern which could be assigned to an orthorhombic unit cell having $a=5.826(2), b=12.437(2)$ and $c=9.489(2) \AA$. Although a full analysis of the corresponding structure from X-ray powder diffraction data has not been attempted in this study it is noted that the powder pattern (exhibiting some additional line splitting) as well as the derived values for the cell constants are strongly reminiscent of those observed for "hexagonal" $\mathrm{SrCoO}_{3-\delta}$. Attempts to improve the crystallinity of samples allowing a more detailed structural study of the low-temperature phase of 
$\mathrm{SrCo}_{0.8} \mathrm{Fe}_{0.2} \mathrm{O}_{3-\delta}$ are in progress. Samples quenched from $1100^{\circ} \mathrm{C}$ after annealing in either air or helium gave a cubic perovskite pattern.

TG-DSC measurements of freshly prepared $\mathrm{SrCO}_{0.8} \mathrm{Fe}_{0.2} \mathrm{O}_{3-\delta}$ recorded in nitrogen atmosphere $\left(P_{\mathrm{O}_{2}} \approx 20 \mathrm{~Pa}\right)$ showed a first-order transition with an endothermic heat effect, $\Delta H=44 \mathrm{~J} \mathrm{~g}^{-1}$, upon heating at about $790^{\circ} \mathrm{C}$. The reverse transition, upon cooling the sample, appeared to be smeared out, taking place at about $50^{\circ} \mathrm{C}$ below this temperature. The TG results showed that, after an initial weight loss of about $1 \mathrm{wt} \%$, the sample locked onto a new composition at about $500^{\circ} \mathrm{C}$. X-ray analysis confirmed transformation to the low-temperature form. A constant plateau was recognized upon further heating to $\sim 790^{\circ} \mathrm{C}$. Then, after a small intermediate weight gain, a sharp weight loss was observed. Fig. 2 shows results from TG-DSC measurements of a sample obtained from the anneal at $700^{\circ} \mathrm{C}$ in helium atmosphere which, as described above, causes full transformation to the low-temperature phase. An almost constant oxygen stoichiometry is seen until the transformation to defect perovskite takes place.

Coulometric titration experiments as described elsewhere [23] have been carried out to determine the composition of the low-temperature phase of $\mathrm{SrCo}_{0.8} \mathrm{Fe}_{0.2} \mathrm{O}_{3-\delta}$. The nonstoichiometry parameter $\delta$ at $P_{\mathrm{O}_{2}}=24 \mathrm{~Pa}$ was found to be 0.49 which suggests that the ideal composition is $\mathrm{SrCo}_{0.8} \mathrm{Fe}_{0.2} \mathrm{O}_{2.5}$. These data agree within experimental error with the results from TG measurements. In order to carry out the

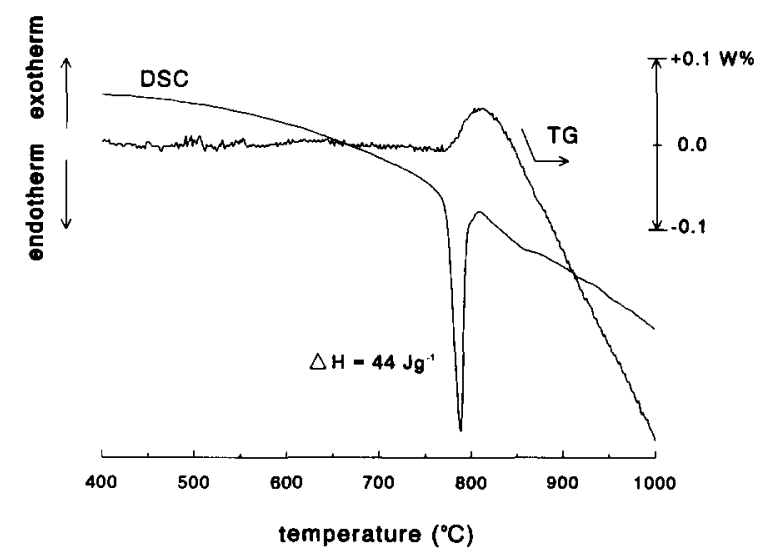

Fig. 2. TG-DSC heating curve of $\mathrm{SrCO}_{0.8} \mathrm{Fe}_{0.2} \mathrm{O}_{3-s}$ after annealing at $700^{\circ} \mathrm{C}$ in a helium gas stream. Heating rate is $10^{\circ} \mathrm{C} \mathrm{min}^{-1}$. analysis of the composition, a sample reduced in $\mathrm{Ar} /$ $\mathrm{H}_{2}$ mixture $\left(\log \left(P_{\mathrm{H}_{2}} / P_{\mathrm{H}_{2 \mathrm{O}}}=1.5\right)\right.$ at high temperature was taken as reference state (assuming dissociation into $\mathrm{Co}, \mathrm{SrO}$ and $\mathrm{Fe}_{3} \mathrm{O}_{4}$ ) leading to $\delta=0.41$ for a freshly prepared sample. These observations support the close relationship between the structure of the low-temperature phase and the brownmillerite lattice as has been proposed earlier [20]. The homogeneity range of the low-temperature phase is probably very limited.

In spite of a simple cubic X-ray pattern displayed by samples $\mathrm{SrCo}_{0.8} \mathrm{Fe}_{0.2} \mathrm{O}_{3-\delta}$, DSC measurements performed in air showed an endothermic peak at about $760^{\circ} \mathrm{C}$. Since the observed heat effect, $\Delta H \approx 2.2$ $\mathbf{J ~}^{-1}$, is very small a tentative explanation would be the presence of a small amount of the low-temperature phase in the sample.

Teraoka et al. [5-7] have investigated the oxygen permeability of $\mathrm{LnCoO}_{3}$-based perovskites upon partial substitution of $A$ and $B$ site cations. The highest permeability was measured for $\mathrm{SrCoO}_{3-\delta}$ substituted with $20 \mathrm{~mol} \%$ of $\mathrm{Fe}$ at the $\mathrm{Co}$-sites. Our own results on $\mathrm{SrCO}_{0.8} \mathrm{Fe}_{0.2} \mathrm{O}_{3-\delta}$ are included in fig. 3, showing that the values are approximately one order of magnitude lower than given by Teraoka et al. $[5,7]$.

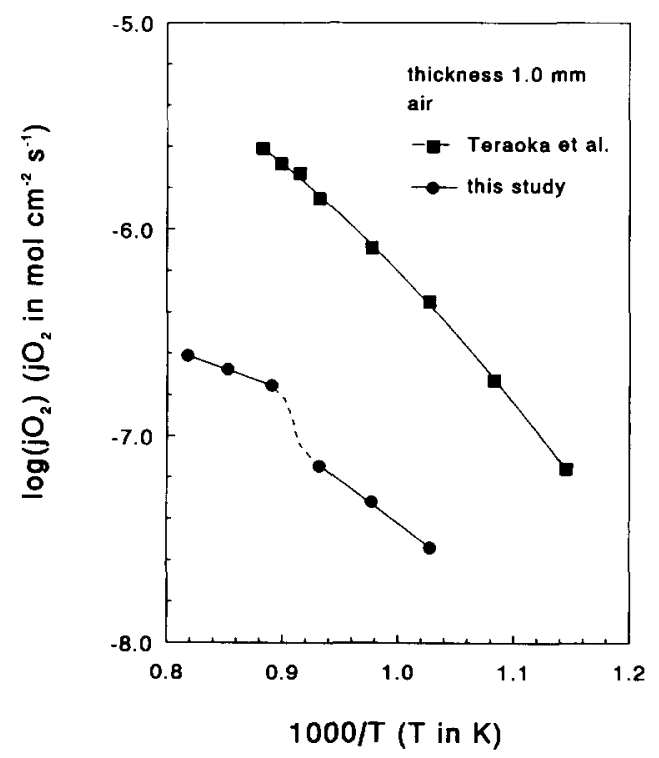

Fig. 3. Oxygen permeability data for $\mathrm{SrCo}_{0.8} \mathrm{Fe}_{0.2} \mathrm{O}_{3-\delta}$. The dashed line is a guide to the eye. 
As shown in fig. 3, the oxygen permeability of $\mathrm{SrCo}_{0.8} \mathrm{Fe}_{0.2} \mathrm{O}_{3-\delta}$ increases slightly upon transition from the low-temperature vacancy ordered state to the high-temperature statistically disordered state (oxygen-deficient perovskite structure) This observation might be interpreted in terms of a two-phase mixture of the low-temperature form and disordered perovskite in the oxygen pressure window imposed across the disc specimen during the permeability measurements below the transition temperature $\left(\sim 790^{\circ} \mathrm{C}\right)$, while the perovskite phase is the stable phase at higher temperatures. It may be recalled that when $\mathrm{SrCo}_{0.8} \mathrm{Fe}_{0.2} \mathrm{O}_{3-\delta}$ is annealed at $700^{\circ} \mathrm{C}$ under helium, the perovskite phase is transformed into the low-temperature phase.

At high temperatures, fast (re)equilibration kinetics $(<30 \mathrm{~min})$ are encountered after a stepwise change of the temperature. Below the order-disorder transition temperature equilibration times between $30-40 \mathrm{~h}$ are required to attain steady-state conditions, irrespective of the thermal history of the sample. This might be explained in terms of a progressive growth of microdomains of the ordered structure. The transient process towards steady-state oxygen permeation, involving the propagation of a composition gradient through the oxide disc after an instantaneous change in the oxygen activity of the gas phase, forms the basis of the so-called "time-lag" method [24]. Preliminary oxygen desorption measurements, however, confirm that the slow equilibration kinetics below the temperature at which the oxygen vacancies disorder cannot be accounted for by a change in the oxygen content of the sample.

At present it is not yet possible to reconcile the discrepancies between our data and those obtained by Teraoka et al. [5-7]. It cannot be excluded that the derived values may be specific to the particular sample under investigation and may be affected by, for example, the preparation technique.

\section{3. $\mathrm{SrCo}_{0.8} B_{0.2}^{\prime} \mathrm{O}_{3-\delta}\left(B^{\prime}=\mathrm{Cr}, \mathrm{Cu}\right)$}

DSC measurements of phases $\mathrm{SrCo}_{0.8} \mathrm{Cr}_{0.2} \mathrm{O}_{3-\delta}$ and $\mathrm{SrCo}_{0.8} \mathrm{Cu}_{0.2} \mathrm{O}_{3-\delta}$, in conjunction with data from oxygen permeability, provide clear evidence of orderdisorder transitions in air with maxima at about 940 and $910^{\circ} \mathrm{C}$, respectively. X-ray analysis of corresponding low-temperature forms obtained by slowly cooling from the sintering temperature gave rather broad and diffuse diffraction lines. Quenching of $\mathrm{SrCo}_{0.8} \mathrm{Cr}_{0.2} \mathrm{O}_{3-\delta}$ in air from $1100^{\circ} \mathrm{C}$ gave a pattern with apparent cubic symmetry supporting the notion that the low-temperature phase transforms to disordered cubic at high temperature. Results from DSC (in nitrogen atmosphere) and permeability measurements for $\mathrm{SrCo}_{0.8} \mathrm{Cu}_{0.2} \mathrm{O}_{3-\delta}$ are given in fig. 4, showing a sharp increase of the permeability at the onset temperature of the order-disorder transition in this phase. The permeability data shown in this figure were obtained from a specimen of $2.0 \mathrm{~mm}$ thickness using a constant heating rate of $0.5^{\circ} \mathrm{C}$ $\min ^{-1}$, after initial equilibration at $750^{\circ} \mathrm{C}$. Fair agreement was obtained with data from steady-state oxygen permeability. Similar observations were made for the chromium substituted material.

\section{4. $\mathrm{La}_{0.6} \mathrm{Sr}_{0.4} \mathrm{CoO}_{3-\delta}$}

$\mathrm{X}$-ray analysis of samples $\mathrm{La}_{0.6} \mathrm{Sr}_{0.4} \mathrm{CoO}_{3-\delta}$ indicated simple cubic symmetry. No change in diffraction pattern was observed in samples obtained from anneal at $700^{\circ} \mathrm{C}$ for $100 \mathrm{~h}$ in a helium stream. However, X-ray diffraction will be inadequate to examine vacancy ordering if samples contain too small microdomains (50-200 $\AA$ ). In such cases characterization by lattice imaging and electron diffraction (HREM) is inevitably required.

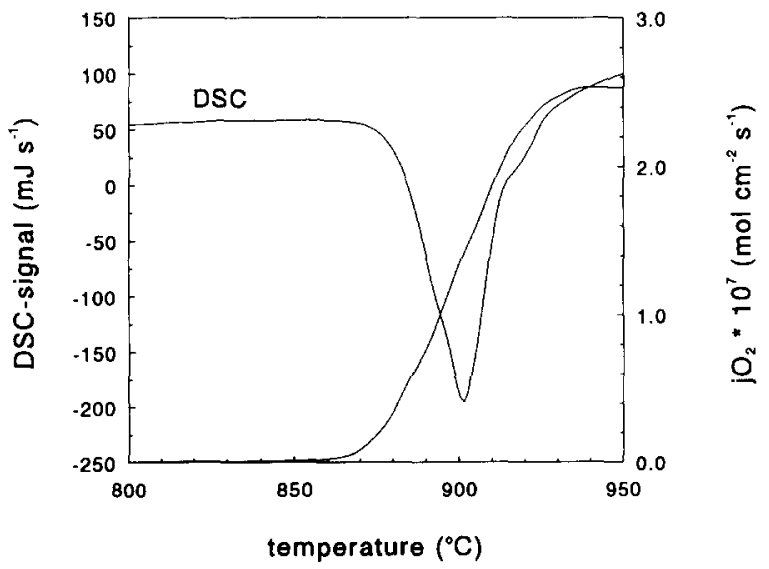

Fig. 4. Oxygen permeability and DSC data for $\mathrm{SrCo}_{0.8} \mathrm{Cu}_{0.2} \mathrm{O}_{3-\delta}$. Curves were obtained using heating rates $0.5^{\circ} \mathrm{C} \mathrm{min}^{-1}$ and $10^{\circ} \mathrm{C}$ $\min ^{-1}$, respectively. 
Positive evidence for an ordered defect structure at low temperatures in samples $\mathrm{La}_{0.6} \mathrm{Sr}_{0.4} \mathrm{CoO}_{3-\delta}$ in this work is provided by data from DSC and oxygen permeability. DSC measurements revealed an endothermic (disordering) peak with heat effect, $\Delta H=9.0 \mathrm{~J} \mathrm{~g}^{-1}$, at about $910^{\circ} \mathrm{C}$ upon heating of a disc sample in air. There is some indication that the transformation on heating proceeds in two steps; the main peak at $910^{\circ} \mathrm{C}$ is preceeded by a smaller peak, $\Delta H \approx 2.5 \mathrm{~J} \mathrm{~g}^{-1}$, with a maximum at about $860^{\circ} \mathrm{C}$. On cooling, a very broad and diffuse peak was observed with onset temperature of about $700^{\circ} \mathrm{C}$.

For an ordered arrangement the associated oxygen ion transport will be slow. Oxygen permeability through $\mathrm{La}_{0.6} \mathrm{Sr}_{0.4} \mathrm{CoO}_{3-\delta}$ at $750^{\circ} \mathrm{C}$ could scarcely be detected (see the discussion below). The permeability increases between 4-5 orders in magnitude to $3 \times 10^{-8} \mathrm{~mol} \mathrm{~cm}^{-2} \mathrm{~s}^{-1}\left(925^{\circ} \mathrm{C}\right)$ above the transition temperature.

Structural evidence for several ordering schemes in $\mathrm{La}_{1-x} \mathrm{Sr}_{x} \mathrm{CoO}_{3-\delta}$ has been reported for $x=0.5$ $[25,26]$ and for $x=0.8[26]$, depending on the oxygen content.

Our results for the oxygen permeability of $\mathrm{La}_{0.6} \mathrm{Sr}_{0.4} \mathrm{CoO}_{3-\delta}$ do not agree with those published by Teraoka et al. [5]. As discussed below, confusing results of the oxygen permeability can be measured upon failure to observe the long-continued transients towards steady-state oxygen permeation. In fig. 5 , the data obtained by Teraoka et al. and initial results on $\mathrm{La}_{0.6} \mathrm{Sr}_{0.4} \mathrm{CoO}_{3-\delta}$ from this study are compared. Apart from the disagreement in magnitude, the curves are very similar. The results given by Teraoka et al. were obtained by stepwise increasing the cell temperature, exposing opposite sides of sealed discs specimens of thickness $1 \mathrm{~mm}$ to air and helium, respectively; no further details are given [5]. The same oxygen pressure gradient has been applied in this study. After the seal treatment at $850^{\circ} \mathrm{C}(15$ min) and subsequent cooling to $650^{\circ} \mathrm{C}$, the helium gas line was connected to the cell assembly. Prior to measurement, the cell was conditioned at the lastmentioned temperature for $30 \mathrm{~h}$, although a steadystate could not be obtained within this time period. After registering the curve shown in fig. 5, the temperature was adjusted to $750^{\circ} \mathrm{C}$ and the permeability monitored as a function of time. As shown in fig. 6 , the permeability decreases with time reaching val-

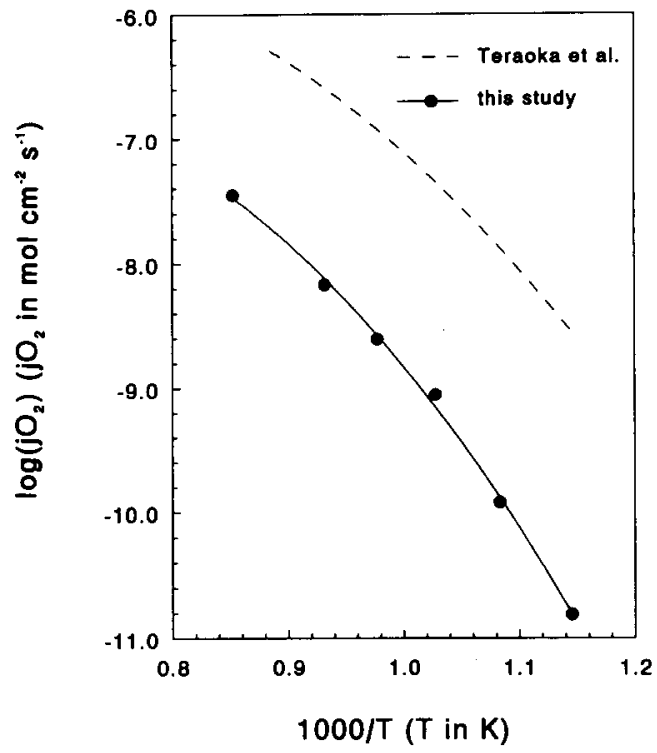

Fig. 5. Oxygen permeability data for $\mathrm{La}_{0.6} \mathrm{Sr}_{0.4} \mathrm{CoO}_{3-\delta}$. As explained in the text, the displayed results may represent an apparent permeation.

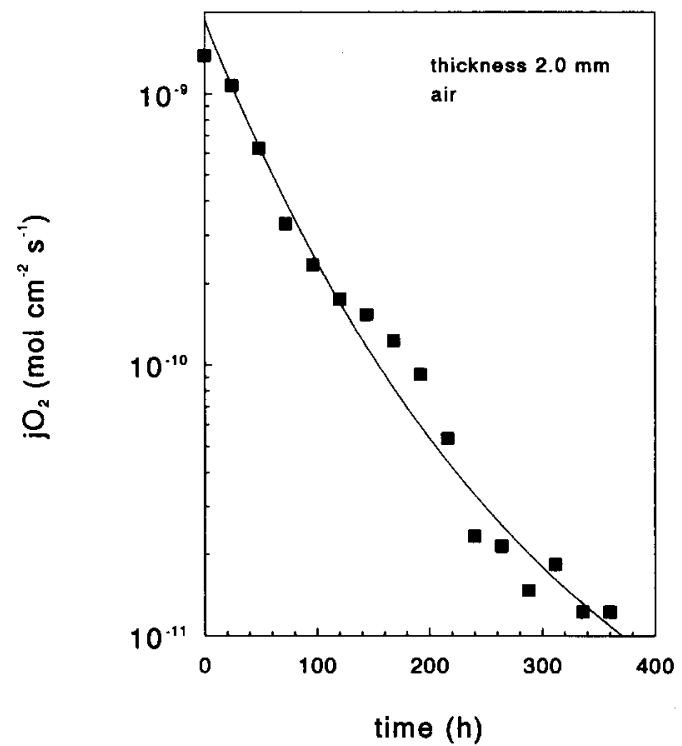

Fig. 6. Transient towards steady-state oxygen permeation observed for $\mathrm{La}_{0.6} \mathrm{Sr}_{0.4} \mathrm{CoO}_{3-\delta}$ at $750^{\circ} \mathrm{C}$.

ues close to the detection limit of our apparatus. First results from oxygen desorption measurements suggest that the major amount of oxygen detected dur- 
ing equilibration is due to adaptation of the oxygen stoichiometry of the oxide disc to the helium gas stream.

\section{Conclusions}

Data were provided which show that in compounds $\mathrm{SrCo}_{0.8} \mathrm{~B}_{0.2}^{\prime} \mathrm{O}_{3-\delta}$ (with $\mathrm{B}^{\prime}=\mathrm{Cr}, \mathrm{Fe}, \mathrm{Co}, \mathrm{Cu}$ ) and $\mathrm{La}_{0.6} \mathrm{Sr}_{0.4} \mathrm{CoO}_{3-\delta}$ the transformation from a lowtemperature vacancy-ordered state to disordered perovskite at elevated temperatures $\left(790-940^{\circ} \mathrm{C}\right)$ is accompanied by a sharp increase of the oxygen permeability (up to $0.3-3 \times 10^{-7} \mathrm{~mol} \mathrm{~cm}^{-2} \mathrm{~s}^{-1}$ ). For $\mathrm{La}_{0.6} \mathrm{Sr}_{0.4} \mathrm{CoO}_{3-\delta}$, it was found that below the vacancy disordering temperature the oxygen permeability decreased with time $(400 \mathrm{~h})$ leaving a material which scarcely permeates $\left(<10^{-12} \mathrm{~mol} \mathrm{~cm}^{-1} \mathrm{~s}^{-1}\right)$. The comparatively high oxygen flux through $\mathrm{SrCO}_{0.8} \mathrm{Fe}_{0.2} \mathrm{O}_{3-\delta}$ observed at intermediate temperatures $\left(600-800^{\circ} \mathrm{C}\right)$ is attributed to the presence of a two-phase mixture of a vacancy-ordered state and disordered perovskite. Annealing under helium at $700^{\circ} \mathrm{C}$ causes transformation of $\mathrm{SrCo}_{0.8} \mathrm{Fe}_{0.2} \mathrm{O}_{3-\delta}$ with perovskite structure into the vacancy-ordered state. The high oxygen fluxes that have been measured through the cobalt-based perovskites above the transition temperature suggest that the oxygen vacancies become randomly distributed into the perovskite layers, rather than that the ordering breaks up into very small domains as has been proposed for the transformation from the low-temperature ordered form (of brownmillerite-type structure) to defect perovskite observed at $850^{\circ} \mathrm{C}$ in the system $\mathrm{Sr}_{2} \mathrm{Fe}_{2} \mathrm{O}_{5}$ [27].

\section{Acknowledgements}

We are grateful to Dipl. Chem. B. Löscher and to Dr. K. Teske (Central Institute of Nuclear Research, Rossendorf, Germany) for carrying out the coulometric titration experiments on $\mathrm{SrCo}_{0.8} \mathrm{Fe}_{0.2} \mathrm{O}_{3-\delta}$. The authors thank Prof. dr. P.J. Gellings for many helpful discussions. Financial support from Air
Products and Chemicals, Inc. for R.H.E. van Doorn is gratefully acknowledged.

\section{References}

[1] D.M. Smyth, Cryst. Lattice Defects Amorph. Mater. 18 (1989) 355.

[2] C.N.R. Rao, J. Gopalakrishnan and K. Vidyasagar, Indian J. Chem. Sect. 23 A (1984) 265.

[3] P. Hagenmuller, M. Pouchard and J.C. Grenier, Solid State Ionics 43 (1990) 7.

[4] B.C.H. Steele, Mat. Sci. Eng. B 13 (1992) 79.

[5] Y. Teraoka, H.M. Zhang, S. Furukawa and N. Yamazoe, Chem. Lett. (1985) 1743.

[6] Y. Teraoka, T. Nobunaga and N. Yamazoe, Chem. Lett. (1988) 503

[7] Y. Teraoka, T. Nobunaga, K. Okamoto, N. Miura and N. Yamazoe, Solid State Ionics 48 (1991) 207.

[8] Y. Teraoka, H.M. Zhang, K. Okamoto and N. Yamazoe, Mat. Res. Bull. 23 (1988) 51.

[9] H.U. Anderson, Solid State Ionics 52 (1992) 33.

[10] W.L. Worrel, Solid State Ionics 52 (1992) 147.

[11] T. Nakamura, G. Petzow and L.J. Gauckler, Mat. Res. Bull. 14 (1979) 649.

[12] A.N. Petrov, V.A. Cherepanov, O.F. Kononchuk and L.Ya. Gavrilova, J. Solid State Chem. 87 (1990) 69.

[13] H.J.M. Bouwmeester, H. Kruidhof, R.H.E. van Doorn and A.J. Burggraaf, to be published.

[14] D.H.A. Blank, H. Kruidhof and J. Flokstra, J. Phys. D 21 (1988) 226.

[15] H.J.M. Bouwmeester, H. Kruidhof, A.J. Burggraaf and P.J. Gellings, Solid State Ionics 53-56 (1992) 460.

[16] J.C. Grenier, S. Ghosbane, G. Demazeau, M. Pouchard and P. Hagenmuller, Mat. Res. Bull. 14 (1979) 831.

[17] Y. Takeda, R. Kanno, T. Takada, O. Yamamoto, M. Takano and Y. Bando, Z. Anorg. Allg. Chem. 540/541 (1986) 259.

[18] J. Rodriguez and J.M. González-Calbet, Mat. Res. Bull. 21 (1986) 429.

[19] J.C. Grenier, L. Fournès, M. Pouchard and P. Hagenmuller, Mat. Res. Bull. 21 (1986) 441.

[20] T. Gibb, J. Chem. Soc., Dalton Trans. (1987) 1419.

[21] P.D. Battle and T.C. Gibb, J. Chem. Soc., Dalton Trans. (1987) 667.

[22] J. Rodriguez, J.M. González-Calbet, J.C. Grenier, J. Pannetier and M. Anne, J. Solid State Commun. 63 (1987) 231.

[23] K. Teske, Kernenergie 24 (1981) 20.

[24] P.J. Gellings and H.J.M. Bouwmeester, Catal. Today 12 (1992) 1.

[25] P.L. Gai and C.N.R. Rao, Mat. Res. Bull, 10 (1975) 787.

[26] J. Kirchnerova and D.B. Hibbert, Mat. Res. Bull. 25 (1990) 585.

[27] J.C. Grenier, N. Ea, M. Pouchard and P. Hagenmuller, J. Solid State Chem. 58 (1985) 243. 